\title{
Rights management and its role in social media markets - Interview with Bill Rosenblatt, President of GiantSteps Media Technology Strategies
}

\section{Bill Rosenblatt}

is the president of GiantSteps Media Technology Strategies (www.giantstepsmts.com), a consulting firm whose clients include content providers and digital media technology companies. Bill bridges the gaps between business and technology in the digital media world. He brings content providers expertise in areas such as digital rights management, content management and distribution, cross-media strategy, and digital product strategy, and he provides technology vendors with market strategy, business development, and product management services. Bill is the managing editor of the Jupitermedia newsletter DRM Watch (www.drmwatch.com) and author of the book Digital Rights Management: Business and Technology (John Wiley \& Sons, 2001).

Keywords: rights, DRM, copyright, creative commons, ACAP, content commerce

Abstract Rights information management is an ongoing and difficult problem for content owners, but it's one that's necessary to solve for those who want to scale up their ability to create new products for an ever-widening set of distribution channels. Bill Rosenblatt, the president of GiantSteps Media Technology Strategies, discusses the issues and how content owners should go about addressing them. He also discusses some of today's thorny issues of digital copyright, such as copyright issues for collaborative and user-generated content, search engines' rights to index commercial content and why DRM has such a bad rep. Journal of Digital Asset Management (2008) 4, 112-122. doi:10.1057/dam.2008.13

Bill Rosenblatt GiantSteps Media Technology Strategies, 1841 Broadway, Suite 200, New York, NY 10023, USA Tel: +1 2129561056 Fax: +1 2122583286 E-mail: billr@ giantstepsmts.com
MM: Bill, why don't we start off with a little bit of an introduction as far as who you are and the company that you run?

BR: Sure. My name is Bill Rosenblatt. I'm the president and founder of Giantsteps Media Technology Strategies. We've been in business since the summer of 2000 . We're a small strategy-consulting firm that deals with digital content rights and infrastructure strategy issues.

We've had clients that span pretty much the entire value chain of content - including content owners, which can include book and magazine publishers, movie studios, record labels, newspaper publishers, journal publishers and so on - educational content institutions.

We've also done work for content service providers of one sort or another - including telcos, aggregators and then technology companies that build mostly software for digital media applications. Also, consumer device companies. Generally, a wide range of clients.
We get into typically strategy-type consulting arrangements. If a media company is looking to accomplish something strategic with digital content, they'll call us in at the beginning of the process, and we'll recommend other vendors to implement the solution or whose products they should be installing or whatever.

That's what we do. As I said, we've been doing it for about 7.5 years.

MM: About two years ago you wrote a paper for the Journal of $D A M$ entitled, "Integrating DAM with DRM - Comparatives and Opportunities for Digital Content Lifecycles."

Before I ask you to reprise the key points you made in that paper, I first of all wanted to start off with a really solid acknowledgment of great work. I read and reread it just recently in preparation for this paper or this interview. It real struck me as crisp, cogent and well written. It really was a great example of both introducing the notion of DRM - placed in the context of 
DRM or DAM. But it also provided some really great examples and some technical illustrations.

Good work!

BR: Thanks!

MM: Should they want to be looking at it, go to the Journal of DAM, Vol. 1, Article 4, Pages 256-270.

That said, Bill, could you give us a quick overview of DRM, for those of us who may not have read both articles, and what's new. BR: Sure.

Well, rights management is a term that means many things. It dates back, I think, to roughly 1995. I think that's the first time it was used in a published forum. I think there was a white paper with that term by someone from the company InterTrust.

In the popular press, it's come to refer to encrypting files and distributing them to consumers through content services such as iTunes and MovieLink and various e-book technologies and so on. It's acquired a negative connotation with regard to media companies locking down their content.

That is actually not so much what I'm referring to in these white papers. I'm really referring to the need for content owners to manage information about the rights that they have to content. The rights that they are conveying down the value chain - whether directly to consumers or to distributors or aggregators or whatever. The rights that they acquire to content that they didn't create. They license content or they acquire it in one way or another.

If you're talking about managing your content - which is, of course, a core subject of the Journal of DAM - then you ought to be talking about the management of information about rights to that content.

In the first white paper, I discussed how you'd integrate rights information about content with the DRM functionality that we normally think about. That's the $\mathrm{B} 2 \mathrm{C}$ functionality. In the time that that white paper was written, there was some thought that the integration of DAM with rights management technologies could be done in a standardized and straightforward way.

In particular, there were some technologies called "rights expression languages," that came along. Such as one called XrML, eXtensible Rights Mark-up Language. Obviously a play on $\mathrm{XML}$ - and indeed, expressed in XML. It was invented by a company called ContentGuard, and in turn, derived from some R\&D work at Xerox PARC.

This is just one example. There are a couple of other examples.

The thought was expressed in this first white paper that you could use a standard language to create metadata about rights to your content, that you could then use as the glue in-between your asset management repository and your secure distribution channels. Whether or not you encrypt the content or watermark it or anything. Just so that information about what rights you have and what rights you are conveying downstream travels with the content.

The first white paper was all about why you need to do that. How doing so can help you distribute your content in a more secure fashion through multiple channels, as well as in the enterprise setting. To help ensure that your content usage adheres to regulatory guidelines or company-wide information usage policies and so on.

It put out this notion that a rights expression language would be the glue - the keystone that would cause all of these systems to be integrated together.

You asked about what's gone on since then. That in a nutshell describes the first of these two white papers.

What's gone on since then is basically - to be honest - the market has taken a look at rights expression languages and yawned. They haven't really been accepted in the market. There are only two examples of real products and services that use rights expression languages and have fairly widespread use.

One is in the mobile content industry, where another rights expression language called, "ODRL," the Open Digital Rights Language, is used in one of the several DRM technologies for mobile content. That's the Open Mobile Alliance's open standard for DRM.

ODRL is a significant rights language. It was invented in Australia by a guy called Renato Ianela.

The folks in the OMA standards body took his work and derived a pretty small subset of that work - an almost trivial subset of that language - and used it in the OMA-DRM Version 1 standard. That's very widely deployed worldwide. It's got a unit-installed base of over half a billion devices worldwide. 
It's as if you took a full-featured programming language like Java or $\mathrm{C}++$ and decided that you would only use the "if" statement and the semicolon that separates statements. Those are the only two elements that you would use, and everything else you're not going to use. So it was a fairly trivial subset.

The other use of rights expression languages that's out there in a big way is Microsoft's use of the XRML language that I referred to for its enterprise rights management (ERM) product — which is called Windows Rights Management Services. This is a product that a corporation or other institution would get in order to protect its internal sensitive information. Like, obviously, Microsoft Office Documents. But not limited to Microsoft Office Documents. When you'd be sending them around in the organization and want to restrict access.

Microsoft does use that technology. It is, in fact, a part owner of ContentGuard - so it makes sense. But other than that...

MM: Bill, is the Adobe Policy Server comparable in that sort of lifecycle? I think they call it LiveCycle. Is that similar?

BR: Yes. LiveCycle Policy Server is a competitive product to Microsoft Rights Management Server. Yes.

MM: With respect to Microsoft's and Adobe's products - is there an apparent leader? Or has it gotten particularly good traction or adoption in one industry or another?

BR: That's a very good question. I think the general consensus on the ERM market is that it's in an early phase. Microsoft can point to some very large-scale adoptions of their products - particularly in the government sector. But also in the enterprise sector.

It's one of these Microsoft things that require you use all Microsoft technology. For example, you need to use Active Directory for your user identity management. You can't be using somebody else's product.

Adobe - I really don't know how widely deployed the Adobe product is. If I had to guess, I'd say it's not as widely deployed as the Microsoft product. It's certainly not marketed as heavily as the Microsoft product. It's not been out on the market as long as the Microsoft product.

The Adobe product is also not a standalone product the way Microsoft's product is. But it is, in fact, as you suggested — part of a suite of products called LiveCycle from Adobe. They have to do, generally, with electronic forms processing and things of that nature.

Certainly Adobe has a lot of customers for the LiveCycle product suite, and some subset of them will be using rights management capabilities.

MM: Understood.

You were bringing us up to speed in terms of new developments of rights information management.

What else have you seen develop? BR: Well, that brings us to the second white paper that I wrote in September 2006 or summer of 2006. That basically says to look beyond your internal use, if you're a content owner of DAM and metadata and so on. Look to the whole value chain.

I gave some examples of how rights information and rights metadata serves as the glue for making rights commerce - what I call rights commerce.

A couple of things have happened. First of all, there have been some third-party services that have grown over the years to provide the kind of rights-based content commerce that is alluded to in the first white paper. The second white paper gives a few examples of them - most of which are still in business.

The best example - the most well built-out example - is CCC or Copyright Clearance Center. This is the US text-publishing industry's rights-licensing collective. Analogous to ASCAP or BMI in the music industry and so forth.

Each major industrial country has one of these. CCC is the one for the US. Not surprisingly, it's the largest in the world. It's also the most sophisticated in the world, in terms of the way that it offers rights licensing commerce.

Let's say you're a professor teaching a class, or you're a republisher of some sort. You want to license the use of some content - let's say an article from a periodical or a journal - to put up on your website, or to send in an e-mail or to do something else with. Or to put into your own print publication.

You can go to the CCC website and choose what content you want. You can search for it and select what rights you want, and you can pay for those rights. All through a very simple, web-based interface. They have something on the order of 2 million different content items that they license the rights to. 
This is what we mean by rights-based content commerce. They represent hundreds or thousands of publishers, and aggregate all the rights in one place.

There are a couple of other examples, but I think that's the best example in terms of the power and comprehensiveness of what they offer.

There are some in the film and music industry that stop short of actually enabling the transaction to be done online. It's expected that if you go to try to find some music to use in the background for your television commercial, you're going to actually negotiate for the rights. You're not going to do it online.

No one's actually done the transaction processing online, but they will let you search. They'll let you view license terms and so forth.

This white paper talks about a bunch of these examples. It notes with perhaps a touch of irony that just about all of these examples are from third parties. They're not from the content owners themselves.

There are a handful of content owners that do have automated rights licensing capabilities such as Cengage - which was formerly Thompson Learning - one of the big educational publishers. But those are pretty rare examples.

The other area that I talk about in terms of what's new - what's changed - is the area of standards in rights information. I say in this white paper that there ain't much happening'. There've been some attempts, but not much has really stuck.

Since writing that white paper, there is one standard that has gotten some momentum or activity. That's a standard called ACAP. That stands for Automated Content Access Protocol. That is focused specifically on the major search engines, and their rights to index content online and make it available in search results.

The primary participants in ACAP - not the only ones, but the primary ones - are news publishers. The Financial Times is the best example of this. Financial Times website FT.com - is, of course, a very heavily trafficked and very popular news website. It's certainly a top-ranked, worldwide news publisher. They are a paid subscription website - such as, for the moment, the Wall Street Journal. Although that's going to change.
You can typically look at today's news on the FT website. Then after the day of publication, you have to be a paid subscriber to look at the article.

However, the big search engines crawl that content, and you can get at it through the search engines, even though it's behind a pay wall on the FT site. That's just one example of what ACAP is trying to address in the market.

The way they're trying to address it is to create a little language and put little metatags in your webpage that convey to a search engine, "Here's what we're allowing you to do or not do with this content."

Currently, there's something called Robots Exclusion Protocol. You use that to say, "Please do not crawl my page for indexing, Mr. Google or Mr. Yahoo." ACAP elected to very sensibly extend the Robots Exclusion Protocol, to make it more fine-grained. To make it say things like, "You can crawl this, but you can only keep the content in your index for x-number of days." Or, "You can index this content, but you're only allowed to display a snippet of text in a user's search results as opposed to the whole page." Or, "This is an image. You can index it, but you can only display a thumbnail." Things of that nature.

This is a very interesting development. I'll stop there, in case you want me to talk about something else.

MM: No, please go on in terms of what the implications of that development are.

BR: It's a very interesting thing. Many people know that the publishing industry and the big three search engines - particularly Google are at odds with one another. Some of the publishers have negotiated various point or ad hoc agreements with search engines, but there's a lot of tension.

Let's talk about Google, because Google is sort of the flashpoint of this issue of allowing Google to scan their books or index their newspaper articles or whatever. Successful negotiations are pretty rare, and there are lots of lawsuits going on.

When you have a lawsuit, the decision of what happens after the suit is over comes down to a judge and perhaps a jury that may not be savvy about the subject matter. Each side will bring an expert witness, and the expert witness will be representing the viewpoint of "them that brung them." I've served in that capacity, so I know what that process is like 
from firsthand experience. The process is insanely expensive. It takes years and it's very risky and unpredictable.

The supposition behind ACAP is that all sides would prefer to have a rational, more predictable and less expensive and quicker solution to this problem. The search engines' position is, "Hey. We're allowed to do this under copyright law." Something called, "Fair use," in the United States, or, analogous laws in other countries. "Don't bother us. Go away. We're acting within our rights."

MM: The basic concept of fair use is that you can lift a passage from a published work -20 to 50 words or whatever - as a way of summarizing or abstracting that work, without being obligated to pay them for that abstract or lift.

BR: Well, not quite, actually. It's one example. Fair use is very, very misunderstood. It's not a very crisp concept, so it's not easy to understand.

Fair use under US law is not the same in other countries. But this will be representative.

Fair use in US law is... Let's say I accuse you of unauthorizedly copying my white paper. If I take you to court, you can say, "Hey. What I did was okay under fair use guidelines." Those are guidelines. It's not like George Carlin's "Seven Dirty Words That You Cannot Say On television." That was fictitious in and of itself.

It's a set of guidelines. There are four guidelines. One is, essentially, "What type of work was it?" Scholarly journal article versus hit record. Another is, "How much of it did you take?" Did you take a snippet or did you take the whole thing. Number three is, "What type of use of it did you make?" Did you use it to criticize the content? Or to summarize it or something? That's on one hand. On the other hand, did you use it to sell to other people? Then the fourth guideline - which is in many peoples' view the most important one... "What affect did your use of the content have on the market for that content?"

In other words, if it's a magazine that's for sale and you dumped a million copies on the market and everyone took the free copy instead of buying it, then you could say, "Yes. That affected the market for the work." It kind of goes down from there.

The argument between publishers and the search engines - particularly Google - is over whether the search engines' use of publishers' content is fair or not. Google says, "Look at the most important criterion: how does this affect the market for the work? We are making your content, Mr. Publisher, discoverable online, so that people can find it in our search results. We are providing links to buy the content on Amazon or wherever else you might be able to buy it. Therefore we are not taking away from the market value of your work. On the contrary, we're enhancing the market value of your work."

The publishers say, "No. Well, maybe that's true. But first of all, you're displaying ads next to those search results, and you're making all the money from the ads. So that's not fair. We should be entitled to a cut of that ad revenue or something. And then, number two, you're scanning those books and making copies in the scanning process. We didn't give you permission to do that. Therefore, that on the face of it is not legal."

These are the types of arguments that they're having in courts or among lawyers.

That brings us back to ACAP. ACAP is an attempt to rationalize this so that the publishers can say, "Yes. We would like our content to be discoverable in many cases - although not in all cases. We would like it to be discoverable under certain terms." Those terms may have to do with how much of it you get to see in the search results - how long you get to see it for. And so forth and so on.

The publishers got together mainly under the auspices of news publishing trade associations, and put out this standard last year. It's a very practical standard. It's not one of these "boil the ocean" standards, and it's also not one of these "Can't we all just get along? Wouldn't it be nice? The world would be in peace and harmony," kind of thing.

It's a pragmatic standard that has a near-term business justification to it. It's out there and it's a nice piece of work. The problem is that in the short-term, there's really little incentive for Google or the other big guys to adopt it. Why should they?

It's somewhat ironic. The content that publishers - the big publishers - like Pearson, the parent company of the Financial Times, or the New York Times Company, or any of those guys... The content that they publish - one could argue - is the best content. It's been 
selected and edited and produced by

professionals who are in the business of selecting, editing and producing the best content.

However, almost as a consequence of that activity, that content is minuscule in volume compared to all the non-commercially published stuff out there. It is a tiny, tiny fraction of all the stuff that's out there on the web. If you're Google and you're indexing the web and you're making ad revenue from searches, then having all this name-brand content in your index is really not going to do very much for your ad revenue.

It may boost it a tiny, tiny bit. But particularly if nobody else has access to this content either - you don't have much incentive to build systems and change your processes and to lose control over your own business - all of which would happen if you adopted ACAP. Therefore, for the time being, the big search engines are not moving on ACAP.

However, there are some startup search engines that are starting to look more seriously at it. There's one in France, Exalead, that is adopting it. So in the longer term, you might see small search engines using this technology. The publishers will mark their content up with ACAP tags. The small search engines will play by the publishers' rules, and they will all of a sudden be able to differentiate themselves from the Googles of the world by being able to say, "Come to us, web-surfing public. We have the premium content. Only here can you get in your search results the news from the Financial Times and the Wall Street Journal and all this good book content, and name-author novels and things of that nature."

Then, if users start to migrate to these startup search engines because they're accessing this content, then there may be some incentives for the big guys to play along. But that's going to take quite a bit of time. As you know, trying to introduce a new search engine into the market and get a sizable audience to come to is a huge, expensive and time-consuming undertaking. MM: Bill, one of the issues undergirding this whole issue of searchable content, and the case that you just made... Much of this premium content represents a minuscule portion of the overall inventory out there.

Would you address or would you begin to speak to the role of social media - blogs, forums, discussions and postings — in the context of rights information management?

They seem to almost be inherently at odds with each other.

BR: Absolutely. That's a great point, Michael. I think that this is a storm brewing in the distance, for sure.

You have people posting their photos on Flickr and posting their videos on YouTube and DailyMotion and Veoh and so forth. Posting their music tracks on MySpace. Posting their blog content.

The dirty little secret about blogs — all the companies who have a vested interest in the blog economy like to brag about how many blogs are there, and how many new blogs are created every microsecond or whatever. The dirty secret is that some huge percentage of them are abandoned. Nobody is reclaiming the storage or deleting them or anything.

I'd wager that something like 75 per cent of all blogs are abandoned - including my music criticism blog, which I abandoned several months ago.

MM: I'm sorry to hear that.

BR:You'd have to read it before jumping to that conclusion.

In any case, there's a lot of stuff out there. There's a novelty period for user-generated content and social media that we're going through. You're starting to see that there are lots of content creators that want to make a living off their content - whether that's directly by selling it, or indirectly by using it to become famous, and then making money some other way. Such as you're a musician and you put your songs up on MySpace, and then you get people to come to your club gigs, and that's how you make your money. Or you sell tee shirts or whatever.

There are lots of content creators - millions, perhaps - who put their stuff out there in the Wild, Wild West of these user-generated content sites and social media networks. They're just putting it out there. Now they're trying to find a way of making a living from it. And they're finding that it's really hard.

There have been cases where - for example - professional photographers put some stuff up on Flickr. And then there was one case where somebody's photo on Flickr ended up in some big print ad for I forget what product. Nike or 
I don't know what it was. Then the

photographer sued.

What can be done about that is the issue.

This is a big, huge thing waiting to happen. The industry has not - by and large - accepted what we now have come to call DRM.

Encrypting of content and so forth.

Yes, there are disadvantages of it from the consumers' perspective. But I would argue that perhaps the biggest reason why DRM has kind of been a failure is because no one wants to pay for it, and therefore the DRM that's out there in the world is not very good. Because there's no incentive to create better DRM.

As a result, the music industry is basically giving up on DRM - at least for permanent downloads. You see a lot of amateur content or small content creators - individual content creators - putting their stuff out there without any form of rights management at all. That's like throwing the baby out with the bathwater.

One attempt to solve this problem - which is a very worthy attempt - is what's called the Creative Commons licensing program. Should I explain what Creative Commons is?

MM: Absolutely. What is "Creative Commons" licensing?

BR: Creative Commons was the brainchild of a Stanford professor named Lawrence Lessig. Larry Lessig. He's an icon among the so-called copyleft. That name is a sort of multidimensional pun.

The copyleft people feel that the media industry has usurped the copyright concept. Copyright is supposed to be a balance of incentives between content creators and the public. The copyleft people feel that it's gone too far towards the big media companies with their highly paid lobbyists and so forth. They're interested in opening up copyright and increasing the size and power of the public domain.

Instead of just protesting about it or telling people to write their congressman or complaining, what they've done is very constructive. They've created a set of copyright licenses that you can use for your content that describe very simple terms that you'd like to offer to the public in ways that you do not need to be a copyright lawyer to understand. That's one of the problems with copyright law: it's very complicated.
If you go to the Creative Common site, they'll tell you about what they have. There are something on the order of half a dozen to a dozen different license attributes that you can choose for your content. You get a file that includes some metatags that you can attach to your content, to describe what those rights are. And a legal agreement that embodies those rights in some legalese - and a little logo that you can attach, so that laypeople can see what you're offering.

The rights are for things like, "I give you the right to share this with others, but you must attribute it to me." That's an example. Another one might be, "I give you the right to include my content in your work," or, "I give you the right to include an excerpt from my content in your work." Simple stuff like that.

An increasing number of individual content creators and small record labels and so on are adopting the Creative Commons licensing framework.

The most interesting thing that Creative Commons has done with respect to commercial media is - late last year and after what I imagine was a lot of philosophical internal debate among the Creative Commons people they introduced another licensing attribute that effectively allows you to sell your content.... It's called CC + .

All these license attributes that Creative Commons have specified are for the free - as in non-commercial - distribution of content under certain restrictions. Such as, "You must attribute it to me," and so forth.

Finally now there's something that says, "I'm licensing this content commercially." There are a handful of startups that have started what you might call mini-CCCs that use Creative Commons and offer the ability to sell usergenerated content under Creative Commons $\mathrm{CC}+$ licensing terms. CCC, in fact, is also very interested in $\mathrm{CC}+$. They helped out in inventing it with Creative Commons in some fashion.

So the application that seems to be of interest here is - let's say you're a blogger. You want to sell your pithy remarks about politics or whatever your subject is. So you attach CC+ licensing terms to your content. This is a nice idea. Does this do anything to address the issue of someone wanting to use your content 
without proper authorization? No. It doesn't do anything to solve that problem.

The Creative Commons people hate DRM. They're anti-DRM. Okay, fine. But the truth of the matter is that Creative Commons is certainly not mutually exclusive with the use of encryption or watermarking or other ways to technologically enforce license terms.

I think as time goes on - in the next year or two years - you're going to see some very interesting things as the Creative Commons copyleft world meets the paid content-licensing world.

You're going to see some startups get into this. You're going to see probably companies like CCC and their equivalents internationally get into this. You may even see commercial publishers start licensing their own content under CC + terms.

MM: Bill, would you direct your comments along these lines, but to what I've now read or heard about as the "networked publication," or the "open-sourced publication?"

BR: What do you mean by "open-source publication?" Do you mean like the open-access model of journal publishing? What are you talking about?

MM: The idea is that as an author, I start to create a book or some sort of work. I create basically a structured wiki. Like an online CMS. It could be a wiki or a blog, but some sort of CMS that allows me to structure things in terms of chapters and subchapters and paragraphs.

I begin to write content - rough draft stuff. Then I open it up to essentially a peer-review process of people that I've granted access to comment, to footnote or challenge or clarify and so on.

Through the course of this, I refine and vet. I edit. I optimize key passages, concepts and so on. At some point, then say, "Okay." I've now got an authored work that's ready for publication, and I'm going to go publish the work. And, "Oh, by the way — thank you very much for helping me create this book." That's the situation you have.

Now I'd think that a number of these unpaid volunteers will take great pride in "having helped out," raise the barn. They will have also participated in creating a community of practice or a community concerned around the work. But then again, it sets up this condition. You were saying, "To what degree do I — as an unpaid member - own or claim ownership of this piece of work that ultimately got published and somebody made money with?"

BR: That's another great question. I'm not a lawyer, although I've learned something about copyright law through my work and writings. I'm a technologist by training. So my natural inclination is to say that it's a matter of expectation management more than anything else.

When you took the time and effort to contribute to this work that is nominally somebody else's work, under what explicit or implicit conditions did you do so? To me, copyright law - at the end of the day — is a practical matter. Perhaps not as a truly legal or philosophical matter. Legal, I'm not qualified to offer an opinion. At the end of the day, it matters what you thought you were signing up for.

There's a good book out there called, "Wikinomics," by Don Tapscott, who's a management consulting guru/futurist type guy. It talks about what's called "crowdsourcing."

He gives a bunch of examples in this book. I actually haven't read the whole thing, but I've looked at some of it. I may get some of the facts wrong, but I'll just spit it out for illustrative purposes.

There was an oil company that had the rights to drill for oil on a patch of land. It was a huge patch of land, and they need to know where exactly they could drill, in order to hit oil deposits. It may have been mineral deposits. Something like that.

They made an announcement. "Anybody who wants to... Here's the information we have. Give us some expertise and some hints about where you think we should be drilling. We'll pay you X-dollars for submitting information to us."

MM: This parallels the "Wisdom of Crowds." Right? The ability to bring together people with multiple diverse backgrounds, and then start to triangulate on what the optimum decision is - or the most accurate prediction.

BR: I think the point that you're hitting on is a key philosophical debate between the fans of Wikipedia and the fans of Encyclopedia Britannica. Do crowds have wisdom? That's the issue.

In the case of this oil or mineral finding exercise, the "crowds" were $\mathrm{PhD}$-level experts in 
geology and so forth. Their contributions were expert, and they ended up being extremely helpful to this company that put out this public challenge. When you're talking about something like Wikipedia, you could argue that it's more like the general public — so it's a little bit different.

If you claim copyright in a work that others contributed to in some way... Then I don't know the answer. In your example, you'd have to really talk to a copyright expert. And I'm betting that they'd only be guessing. That's really uncharted territory.

MM: The thing I wanted you to speak to or to get into is, how does a company whether they're a commercial firm that sells widgets or provides services - or a content firm - be they media and entertainment or publishing... What is the underlying information rights strategy for incorporating the wisdom of the crowds - or, again, unpaid volunteers - in the creation of these authored, and ultimately copyrighted and controlled properties?

BR: I think the answer is, once again, a matter of expectation management - combined with some legalistic "hiney-covering." If you want to solicit contributions from the public...

MM: That would be a fairly simple, "Here. If you want to participate in this blog or in this wiki or in this discussion, here is basically a waiver." Or I agree that whatever comments I provide here are part of an overall authored work, and I give up all my rights.

BR: Or they become the "property of..." MM: Right.

BR: The best example of this is to go look at MySpace. MySpace is owned by one of the biggest media companies in the world - News Corp. People post stuff on MySpace all the time. Go read their terms of service. There's a document on every website except for the most trivial websites, called, "Terms of Service" document. That's a legal web page.

I certainly don't know offhand what it says, but I'm sure it says something like, "All submissions become the property of News Corp." It's that simple. There may be certain carve-outs for things like when you're a band and you want to sell your music on MySpace through the MySpace MyStores feature. Then of course, different rules apply.
But if you're just posting stuff onto a MySpace page, then certainly...

MM: I'm certain there is probably reference to the digital millennium copyright act, of which perhaps the most salient portion is that I'm going to upload stuff that I believe I have the copyright to do so. If I find stuff here that some copyright owner claims ownership of, I will, however, agree to take it down within a certain period of time.

BR: Well, News Corp has that responsibility. But yes, other than that, that's right. If I put up something, as you say, the rules are that I'm making a representation that I have the right to put this content up. If the owner of that content begs to differ, then they can issue what's called a DMCA takedown notice. The site operator in this case, MySpace/News Corp - has the obligation to remove it. The matter ends there, under current law.

Some of the big media companies - notably, Viacom - are trying to change that. Viacom's suing YouTube over this type of issue. And there are technologies out there, some of which MySpace is actually using, that purport to block copyrighted content before it can be uploaded.

There are technologies called content identification technologies that will look at a file and try to figure out what song or movie or television show or whatever it is that the file contains. If it's a copyrighted work that's in their database of copyrighted works, then it will prevent the content from being uploaded. That's how that works.

MM: That's what I really wanted you to speak to, Bill. Again, in the idea of digital supply chains, rights information management has now emerged as a new category of metadata. It's a new set of business policies.

If you could, quickly reprise or summarize from a content owner's perspective. Perhaps a medium-sized one. How does one start to go about thinking of building a database of these sorts of things? And creating and managing policies for staying current and staying within the law?

BR: Well, it's a big task. If you're a content owner, then you probably have rights information. Some rights information you may have in various bits and pieces somewhere or other - such as on somebody's spreadsheet. MM: Or in a contract. 
BR: Or in a legal contract. Minimally. Or maybe on a piece of paper somewhere. Maybe if you're really lucky, in someone's FileMaker Pro database. There may be some other information about rights that you don't have that's not captured.

In an ideal world, people would spend their time creating metadata about rights. There would be lots and lots of very rich metadata about rights. But Michael, you've been around this field a long enough time that you know better than just about anyone else that that's very difficult to expect anyone to do. It's a very time-consuming task to create all that metadata. It requires a lot of skills. The people who would be normally expected to create that metadata may not have them - such as legal ability or library science, or whatever.

The struggle that's going on right now in a lot of media companies is, how do they get a bang for the buck solution to this problem? How do they create some rights metadata that enable them to have some understanding of what they've got, as opposed to no understanding of what they've got?

For example, in magazine publishing you've got a metadata standard called PRISM. That has one or two fields for rights metadata among all the other metadata fields that they specify in PRISM. Those are for whatever type of information you want.

Some publishers are using those fields to put in things like "Call Chris at extension 6144."

MM: Right.

BR: It's a tough problem. There's one company that I can't name - a big, huge video-oriented media company - that started to address this problem a couple years ago by having hundreds of file drawers of contracts scanned. They started with that. That took a huge amount of effort just to get them into digital form in any way, shape or form at all.

Then there was a company called Real (pronounced the Spanish way, "Ray-AHL") Software in Hollywood. It had some rights information management software for movie studios. They had the technology that purported to use natural language processing and artificial intelligence techniques to examine contracts and extract our rights metadata from contracts. I don't know how well that stuff worked.
This is to give you an idea of the lengths that some companies will go to solve this problem. It is not an easy problem to solve. But the only way to approach solving it that makes any sense is to be expansive about the business benefits that you can derive from proper management of rights information. To think broadly about that.

The companies that think of this as simply a way of reducing paperwork or being able to lay off a couple of clerical workers are not going to get there. They're not going to justify that well enough.

They need to be able to think in the terms that I laid out in these white papers, which are... "Here are all the new products and services that you could launch with your content if you had the rights information available easily. You could marshal it to feed it to these downstream distribution channels."

If you had that, you could launch these new products and services with your content, without having to build a new silo every time. That would bring you in a lot of incremental revenue and so forth and so on. That will get you to the level of investment that you need. MM: Right.

As we begin to wrap this up, Bill - in terms of our interview today, any kind of summarizing comments in terms of what we've covered today?

BR: Well, I guess - gosh — it's a very interesting field. It covers a lot of territory. But I'd say two things. First of all, there really is a way to plan and justify prudent investment in rights information management if you're a content owner. That is through what I call "requirements harvesting."

That means content owners by and large, with certain exceptions, don't do a great job of new product planning. They're sort of stuck in, "Okay. Here's our annual operating plan," and then, "Here's our warm and fuzzy 5-year strategic vision," which includes name-yourfavorite-aphorism about growth and piece and harmony and love and understanding.

There isn't much in terms of... MM: Shareholder wealth.

BR: There you go. Right.

The idea of new product development and new product planning based on your content is something that, if it's done more methodically, 
can lead to, "Oh. I see. We need to marshal our rights information management so that we can use it in an automated and predictable fashion."

If you go at it from that standpoint, you can figure out what you need and justify the investment, instead of saying, "Well, maybe if we build this, we'll be able to fire a couple of people," or, "Build it and they will come." Both of which are losing propositions, in my experience.

We've worked with media companies to help them with this type of methodology, in justifying these investments. That's one conclusion. That's the key to figuring out what you need, and then going ahead and making a plan and doing it.

The other thing I'll say in conclusion is, you brought up this whole area of social media vis-àvis rights and commercial media. I think this is going to be a huge area. The worlds of commercial and social media are colliding.
You've seen things like CBS buying Last.fm. Or News Corp buying MySpace. That is just the tip of the iceberg. In a way, that's a superficial way of colliding or combining these two worlds. There are going to be all kinds of things about managing rights to user-generated content or releasing commercial content into user-generated networks. This is going to be a big, fascinating yet very messy world. The problems that it engenders - just like what you referred to, Michael, with your Wiki-type example — are going to be monumental. They're going to keep people like myself hopefully employed for some time to come.

MM: Excellent. I look forward to touching base with you in another 6 or 12 months, to get an update on those key trends.

BR: Fantastic.

MM: Great. Thanks so much, Bill.

BR: Thank you. I really enjoyed it, Michael. 